OPEN ACCESS

Edited by:

Simon Michael Cutting,

Royal Holloway - University

of London, UK

Reviewed by:

Joseph Sorg,

Texas A\&M University, USA

Peter Setlow,

University of Connecticut Health

Center, USA

*Correspondence: Jason Brunt

jason.brunt@ifr.ac.uk

Specialty section:

This article was submitted to Microbial Physiology and Metabolism,

a section of the journal

Frontiers in Microbiology

Received: 29 June 2016 Accepted: 12 October 2016

Published: 28 October 2016

Citation:

Brunt J, van Vliet AHM, van den Bos F, Carter AT and Peck MW (2016) Diversity of the Germination Apparatus in Clostridium botulinum Groups I, II, III, and IV.

Front. Microbiol. 7:1702.

doi: 10.3389/fmicb.2016.01702

\section{Diversity of the Germination Apparatus in Clostridium botulinum Groups I, II, III, and IV}

\author{
Jason Brunt ${ }^{1 *}$, Arnoud H. M. van Vliet ${ }^{1,2}$, Fédor van den Bos ${ }^{1}$, Andrew T. Carter ${ }^{1}$ and \\ Michael W. Peck ${ }^{1}$
}

1 Gut Health and Food Safety, Institute of Food Research, Norwich, UK, ${ }^{2}$ School of Veterinary Medicine, Faculty of Health and Medical Sciences, University of Surrey, Guildford, UK

Clostridium botulinum is a highly dangerous pathogen that forms very resistant endospores that are ubiquitous in the environment, and which, under favorable conditions germinate to produce vegetative cells that multiply and form the exceptionally potent botulinum neurotoxin. To improve the control of botulinum neurotoxin-forming clostridia, it is important to understand the mechanisms involved in spore germination. Here we present models for spore germination in $C$. botulinum based on comparative genomics analyses, with $C$. botulinum Groups I and III sharing similar pathways, which differ from those proposed for C. botulinum Groups II and IV. All spores germinate in response to amino acids interacting with a germinant receptor, with four types of germinant receptor identified [encoded by various combinations of gerA, ger $B$, and gerC genes (ger $X)$ ]. There are three gene clusters with an $A B C$-like configuration; $A B C$ [gerX1], ABABCB [gerX2] and ACxBBB [gerX4], and a single CA-B [gerX3] gene cluster. Subtypes have been identified for most germinant receptor types, and the individual GerX subunits of each cluster show similar grouping in phylogenetic trees. C. botulinum Group I contained the largest variety of gerX subtypes, with three gerX1, three gerX2, and one gerX3 subtypes, while C. botulinum Group III contained two gerX1 types and one gerX4. C. botulinum Groups II and IV contained a single germinant receptor, gerX3 and gerX1, respectively. It is likely that all four $C$. botulinum Groups include a SpoVA channel involved in dipicolinic acid release. The cortex-lytic enzymes present in C. botulinum Groups I and III appear to be CWIJ and SleB, while in C. botulinum Groups II and IV, SleC appears to be important.

Keywords: C. botulinum, C. sporogenes, spore, germination, germinant receptors, cortex-lytic enzymes

\section{INTRODUCTION}

All strains of Clostridium botulinum form the highly potent botulinum neurotoxin, the agent responsible for botulism, a severe and often fatal neuroparalytic disease of humans and animals (Hatheway, 1988; Hauschild, 1989; Lindström et al., 2009; Peck, 2009; Peck et al., 2011; Johnson, 2013; Carter and Peck, 2015). There are seven confirmed botulinum neurotoxins (types A to G), and approximately forty different subtypes (Carter and Peck, 2015; Hill et al., 2015; Williamson et al., 2016). The botulinum neurotoxin is the most powerful toxin known, with as little as 30-100 ng sufficient to cause human botulism. Humans 
are susceptible to three distinct types of botulism. Foodborne botulism is an intoxication associated with consumption of botulinum neurotoxin preformed in food. Infant/intestinal (adult) botulism is an infection associated with growth and neurotoxin formation in the infant gut, while wound botulism is an infection associated with growth and neurotoxin formation in a wound (often following drug abuse). In humans, symptoms of botulism typically commence with blurred vision, followed by an acute symmetrical descending bilateral paralysis, and eventually paralysis of the respiratory/cardiac muscles (Hatheway, 1988; Hauschild, 1989; Lindström et al., 2009; Peck, 2009; Peck et al., 2011; Johnson, 2013; Carter and Peck, 2015).

All strains of C. botulinum also form highly resistant endospores that are ubiquitous in the environment and may contaminate foods (Dodds, 1992; Carlin et al., 2004; Peck, 2010; Peck et al., 2010; Barker et al., 2016) and which, under favorable conditions germinate to produce vegetative cells that multiply and form neurotoxin. Spore germination is commonly initiated by a germinant receptor (GR) responding to nutrient germinants, and is followed by the release of dipicolinic acid (DPA) and partial core hydration. Next, cortexlytic enzymes (CLEs) degrade the spore cortex, permitting additional core hydration and core expansion. Since spore germination is the key stage in the transition from dormant spore to vegetative cell, a greater understanding of the mechanisms involved in this process may contribute to an improved control of C. botulinum. Spore germination is relatively well understood in Bacillus (Setlow, 2014), and significant developments have been recently made in various species of Clostridium, including C. botulinum (Broussolle et al., 2002; Alberto et al., 2003; Paredes-Sabja et al., 2008b, 2009a; Burns et al., 2010; Adam et al., 2011; Banawas et al., 2013; Brunt et al., 2014, 2015; Meaney et al., 2015; Kevorkian et al., 2016).

Clostridium botulinum is not a homogeneous species, but a collection of four discrete bacterial groups (C. botulinum Groups I-IV) that share the common feature of forming botulinum neurotoxin. While all are obligately anaerobic bacteria, the four groups are sufficiently distinct to merit allocation to individual species. For each C. botulinum group, closely related non-toxigenic bacteria are known. C. botulinum Group I (proteolytic C. botulinum) is a major cause of botulism in humans (foodborne, infant, and wound), and strains form one or more neurotoxins of types A, B, or F (Hatheway, 1988; Peck et al., 2011; Johnson, 2013). C. botulinum Group I is a highly proteolytic and mesophilic bacterium that forms very heat resistant spores. The "Botulinum cook" $\left(121^{\circ} \mathrm{C} / 3 \mathrm{~min}\right)$ given to low acid canned foods is designed to inactivate these spores (Peck, 2009). C. sporogenes and C. botulinum Group I are closely related bacteria (Collins et al., 1994; Sebaihia et al., 2007; Jacobson et al., 2008; Carter et al., 2009; Bradbury et al., 2012). C. sporogenes is a significant cause of food spoilage (McClure, 2006), and due to its close physiological similarity to C. botulinum Group I is widely used as a surrogate in demonstrating the effectiveness of food preservation processes (Brown et al., 2012; Taylor et al., 2013). Recent analysis indicates that several strains that form type B neurotoxin, and were previously classified as C. botulinum Group I, appear more like strains of $C$. sporogenes that have acquired a neurotoxin gene (Carter et al., 2009; Weigand et al., 2015; Williamson et al., 2016). C. botulinum Group II (non-proteolytic C. botulinum) is an important cause of foodborne botulism in humans, and is a concern for the safe production of minimally heatprocessed refrigerated foods (Peck and Stringer, 2005; Peck, 2006; Peck et al., 2008). Strains form a single neurotoxin of type B, E, or F. C. botulinum Group II is a saccharolytic and psychrotrophic bacterium that forms spores of moderate heat resistance (Peck, 2009; Stringer et al., 2013). Strains of C. botulinum Group III form a single neurotoxin of type C or type $\mathrm{D}$ or more commonly a hybrid neurotoxin that comprises elements of each (type $\mathrm{C} / \mathrm{D}$ or $\mathrm{D} / \mathrm{C}$ ), and are responsible for botulism in a wide range of animal species (Lindstrom et al., 2004; Sharpe et al., 2008; Woudstra et al., 2015). C. botulinum Group III is a saccharolytic and mesophilic bacterium that closely resembles $C$. novyi and C. haemolyticum (Skarin and Segerman, 2014) and forms spores of high heat resistance (Sasaki et al., 2001; Woudstra et al., 2015). C. botulinum Group IV (also known as C. argentinense) is the least studied C. botulinum group. This proteolytic and mesophilic bacterium forms type $G$ neurotoxin and spores of high heat resistance. While experiments have shown its type $G$ toxin to be toxigenic in animals, it has been weakly associated with botulism cases (Peck, 2009). Closely related non-toxigenic bacteria include C. subterminale.

The rapid technical development in genome sequencing, as well as the reductions in cost, now allow for comparative genomics of large collections of bacteria. In the present study, genome sequences have been used to establish the spore germination pathways, from germination receptors to sporecortex-lytic hydrolases, for C. botulinum Groups I-IV. These bioinformatic approaches have been coupled to experimental analysis of germination stimuli. C. botulinum spores were found to contain GRs that responded to amino acids, and CLEs that resembled those described in other species. Spore germination appeared similar in C. botulinum Groups I and III, with subtle differences to that in C. botulinum Groups II and IV.

\section{MATERIALS AND METHODS}

\section{Genome Sequences Included in This Study}

Genome sequences were downloaded in FASTA file format as contigs or complete genome sequences from the NCBI website ${ }^{1}$. Supplementary Table S1 contains GenBank/EMBL/DDBJ accession numbers of each genome sequence used, as well as assignment to C. botulinum Groups I-IV. The C. botulinum Group I data set comprised 92 C. botulinum and 8 C. sporogenes genome sequences, while those for C. botulinum Groups II and III comprised 24 and 31 C. botulinum genome sequences,

\footnotetext{
${ }^{1}$ http://www.ncbi.nlm.nih.gov/genome/browse/
} 
respectively. A single C. botulinum Group IV genome was also included.

\section{Phylogenetic Analyses}

A combined phylogenetic tree of all 156 genome sequences was generated using Feature Frequency Profiling with FFPry version $3.19^{2}$ (Sims et al., 2009) with a word length of $L=18$ as described in (van Vliet and Kusters, 2015). The program FFPboot was used for bootstrap analysis of the tree generated, using the default settings, and run for 100 replicates. Individual phylogenetic trees of C. botulinum Groups I-III were generated from core genome single nucleotide polymorphisms (SNPs), identified using the parSNP version 1.2 program from the Harvest suite (Treangen et al., 2014) with the "-a $13-c-x$ " switches, with bootstrap values provided by the ParSNP output.

\section{Comparative Genomics of GerX and Cortex-Lytic Enzymes}

Genome sequences were provisionally annotated using Prokka version 1.12 (Seemann, 2014) and used for comparative genomics using Roary version 3.5.7 (Page et al., 2015). The gerX clusters and associated upstream and downstream genes were extracted from the comparisons to assess conservation of the genomic organization of the gerX clusters, as outlined in Figure 1D and Supplementary Table S2. Alignments were made with MEGA version 6.0 (Tamura et al., 2011), and used for generation of phylogenetic trees using the Neighbor Joining option. Figtree ${ }^{3}$ was used for annotation of phylogenetic trees. Genome sequences were genotyped for the different gerX clusters by in silico hybridisation using $60 \mathrm{nt}$ oligonucleotides from the different gerX gene clusters, using the Microbial In Silico Typing (MIST) software package (Kruczkiewicz et al., 2013) and the NCBI Blast+ version 2.28 executables. Representative gene numbers for the gerX clusters and CLE genes from reference genomes are given in Supplementary Table S2. BLAST searches of the Prokkaannotated genomes were used to assess the level of variation between predicted GerX and CLE proteins encoded by the genomes. All generated data and phylogenetic trees are available in Supplementary Data Sheet 1.

\section{Protein Bioinformatics}

Relevant predicted amino acid sequences of the germination proteins of interest were imported into the Geneious 8.1.7 software (Biomatters ${ }^{4}$ ) package from NCBI. Signal cleavage sites were predicted using sigcleave, which is part of the EMBOSS suite (Rice et al., 2000). Protein domain analysis was performed using Pfam (Punta et al., 2012) and InterProScan to annotate proteins with families and domains (Quevillon et al., 2005). Transmembrane helices were characterized using Transmembrane Hidden Markov models (TMHMM; Krogh et al., 2001). Protein structure predictions were also analyzed using the PSIPRED Protein Sequence Analysis Workbench (Buchan et al., 2013).

\footnotetext{
${ }^{2} \mathrm{http}: / /$ sourceforge.net/projects/ffp-phylogeny/

${ }^{3}$ http://tree.bio.ed.ac.uk/software/figtree/

${ }^{4} \mathrm{http}: / /$ www.geneious.com
}

\section{Bacterial Strains and Growth Conditions}

Clostridium sporogenes strain ATCC 15579 was grown at $37^{\circ} \mathrm{C}$ in anaerobic tryptone-yeast-glucose medium (TYG). Escherichia coli strain Top10 (Invitrogen) was used for plasmid maintenance and the E. coli strain CA434 (Purdy et al., 2002) was used for conjugal transfer. E. coli strains were grown aerobically in Luria-Bertani medium (LB) at $37^{\circ} \mathrm{C}$. Where appropriate, growth medium was supplemented with antibiotics at the following final concentrations; chloramphenicol $25 \mu \mathrm{g} / \mathrm{ml}$, cycloserine $250 \mu \mathrm{g} / \mathrm{ml}$, thiamphenicol $15 \mu \mathrm{g} / \mathrm{ml}$, erythromycin $2.5 \mu \mathrm{g} / \mathrm{ml}$, and the chromogenic substrate 5-bromo-4-chloro -3-indolyl- $\beta$-D-galactopyranoside (X-Gal) $80 \mu \mathrm{g} / \mathrm{ml}$. All bacterial media supplements were purchased from Sigma.

\section{PCR and Cloning}

Constructed mutants and plasmids utilized in this study are presented in Supplementary Table S3. Primers used for verification of successful insertion events are also listed in Supplementary Table S3. PCR experiments were performed using Phusion High-Fidelity PCR Master Mix with GC Buffer kit (Thermo Fisher). Plasmid isolation and PCR purification was performed using the Wizard Plus SV Minipreps DNA Purification System and the Wizard SV Gel and PCR CleanUp System (Promega) respectively, as defined in the provided Technical Manual. Chromosomal DNA isolation from potential mutants was prepared as previously described (Sebaihia et al., 2007).

\section{Generation and Characterisation of spoVA Mutants and Their Complements}

Mutants of C. sporogenes strain ATCC15579 were generated using the Clostron system as previously described (Brunt et al., 2014). Briefly, target sites were identified using the Perutka method (Perutka et al., 2004) and mutants were generated (Supplementary Table S3) as described (Heap et al., 2010). Re targeted introns were synthesized and ligated into the pMTL007C-E2 vector by DNA 2.0 (Menlo Park, USA). Retargeted intron plasmids were transformed into E. coli CA434. Confirmed (sequenced) plasmids were then transferred by conjugation into their respective clostridial host. For mutant complementation, plasmid pMTL83151 was used (Heap et al., 2009). Primers bearing restriction sites compatible with pMTL83151 (BamHI and NheI) were used to amplify the spoVA gene cluster and its $5^{\prime}$ non-coding region, covering the predicted putative promoter. The resulting PCR product was digested with BamHI and NheI before being ligated into the pMTL83151 plasmid. Following confirmation by sequencing, complementation plasmids were transconjugated into their respective mutants using E. coli CA434 as described previously. The capacity of C. sporogenes spoVA mutants to form spores was assessed following incubation in anaerobic TYG broth at $37^{\circ} \mathrm{C}$ for $72 \mathrm{~h}$. Spore formation was visualized every $24 \mathrm{~h}$, in at least twenty fields, using phase-contrast microscopy. The number of heat resistant spores formed after $72 \mathrm{~h}$ was determined by heating the culture $\left(80^{\circ} \mathrm{C}\right.$, $15 \mathrm{~min}$ ), serial dilution in $0.85 \%$ saline, and plating in 

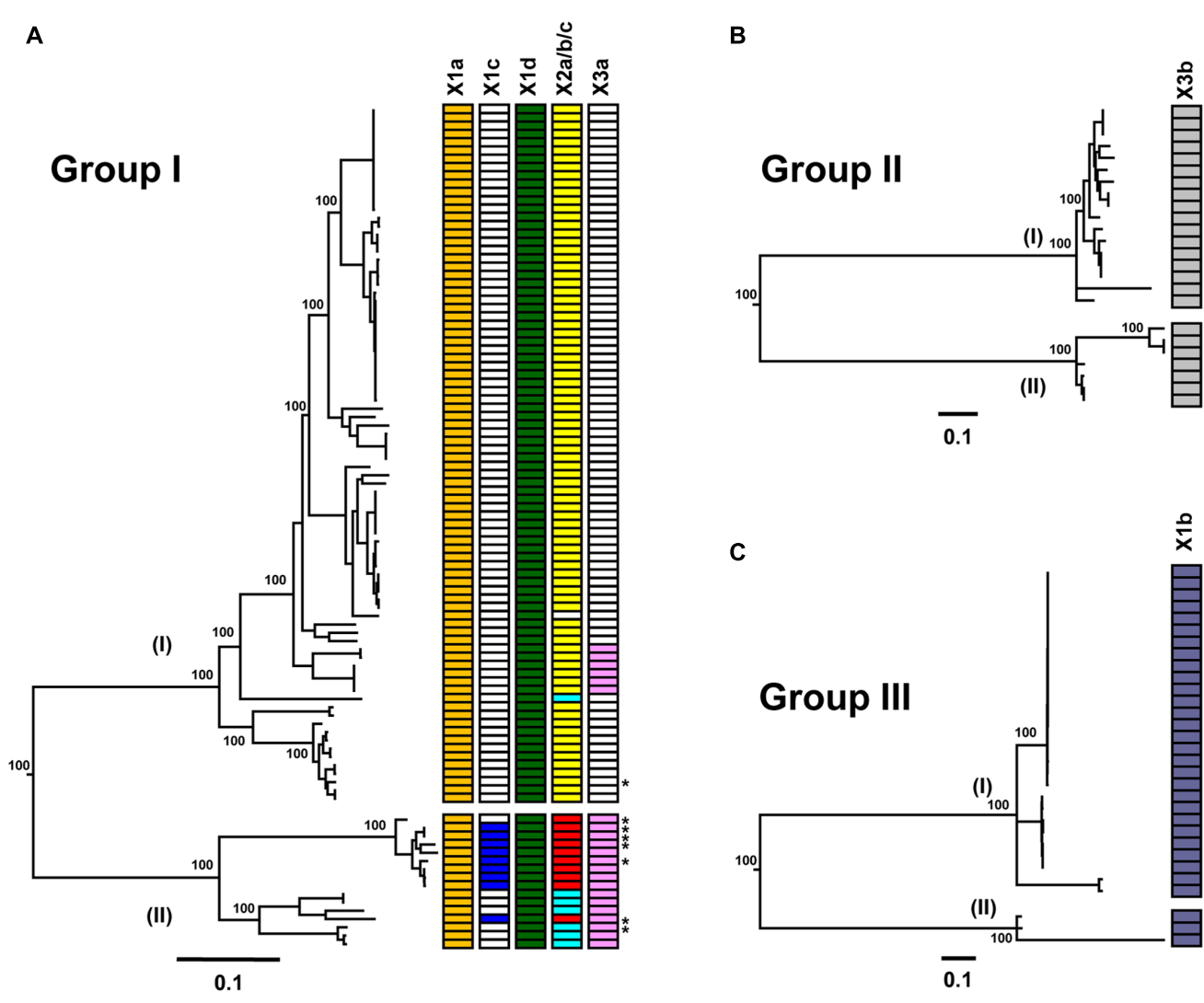

0.1

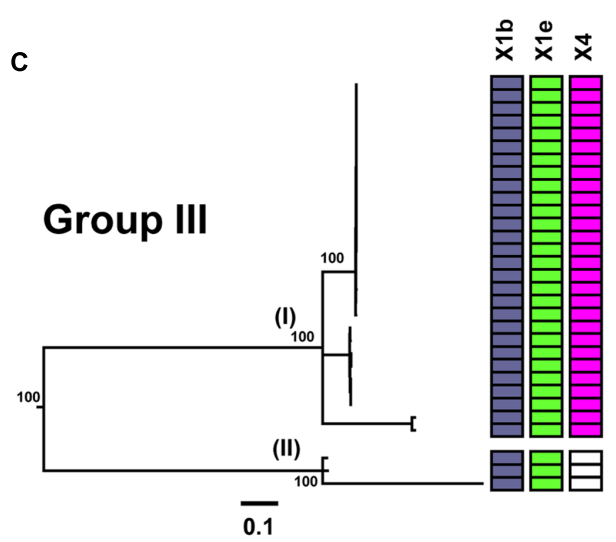

D

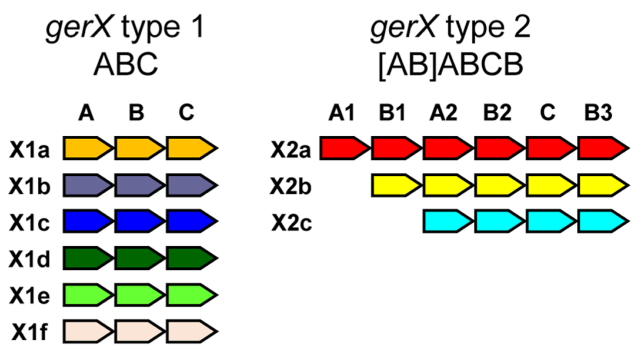

gerX type $3 \quad$ gerX type 4 CAB ACXBBB

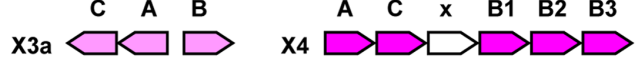

$\mathrm{x} 3 \mathrm{~b}<<\square$
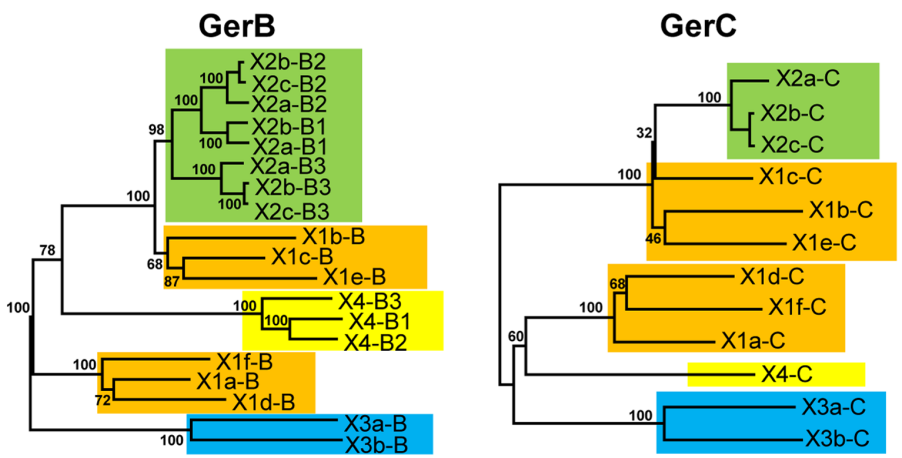

FIGURE 1 | Distribution of GerX receptor gene clusters in Clostridium botulinum Groups I to IV and C. sporogenes genomes. (A) Distribution of gerX types in C. botulinum Group I and C. sporogenes genomes. The asterisks represent $C$. sporogenes strains. The colors in trees (A-C) correspond with the colors attributed to each individual gerX subtype shown in (D). White blocks represent absence of the specific germinant receptor subtype. (B) Distribution of gerX types in C. botulinum Group II genomes. (C) Distribution of gerX types in C. botulinum Group III genomes. A full list of isolates included and their gerX gene clusters is given 


\section{FIGURE 1 | Continued}

in Supplementary Table S4. The phylogenetic trees in (A-C) are based on single nucleotide polymorphisms (SNPs) as determined using ParSNP (Treangen et al., 2014). Values shown at branches represent bootstrap values provided by ParSNP. (D) Genetic organization of the gerX subtypes. Type 1 represents the gerABC layout, Type 2 represents the (AB) ABCB layout, Type 3 the CA-B layout as a bicistronic gene cluster, and Type 4 an ACxBBB gene cluster. Subtype gerX1f is only found in $C$. botulinum Group IV which is not shown in (A-C). (E) Phylogenetic tree of Ger proteins. Representative reference genomes used are given in Supplementary Table S2. Colors represent the clustering based on GerX type. GerX type 1 is highlighted in gold, GerX type 2 in green, GerX type 3 in blue, GerX type 4 in yellow. The GerA, GerB, and GerC amino acid sequences each cluster into different subtypes. GerA, GerB, and GerC amino acid sequences were aligned with MEGA v 7.0, followed by creation of a phylogenetic tree using the Neighbor joining algorithm. Values shown at branches represent bootstrap values from 100 replicates.

triplicate on to TYG agar before incubation anaerobically $\left(37^{\circ} \mathrm{C}\right.$, $72 \mathrm{hrs})$.

\section{RESULTS AND DISCUSSION}

\section{Core Genome SNP Analysis of C. botulinum Genomes Confirms Clustering into Four Distinct Groups}

To investigate the relationship between germination genes and genome phylogeny, we obtained 156 C. botulinum genome sequences. These were first clustered using feature frequency profiling (Sims et al., 2009; van Vliet and Kusters, 2015), to obtain an overview of the phylogenetic relationships within these 156 genome sequences. This initial analysis showed that the 156 genomes separated into four distinct phylogenetic groups (Supplementary Figure S1), thus giving 100 C. botulinum Group I (including C. sporogenes), 24 C. botulinum Group II, 31 C. botulinum Group III, and 1 C. botulinum Group IV genomes. The phylogenetic relationships within each group were determined using core genome SNP analysis, highlighting that Groups I-III each consisted of two distinct clusters of isolates, thus confirming the heterogeneity of the C. botulinum species. All but one of the C. sporogenes genomes clustered in C. botulinum Group I (lineage II), together with nine C. botulinum genomes forming a more distantly related lineage (Figure 1A, lineage II and Supplementary Table S4). It was recently reported that C. botulinum strains CDC68016, ATCC 51387, Prevot 1662, Osaka05, and Okayama2011 were defined as C. sporogeneslike strains that may have acquired a neurotoxin gene via horizontal transfer of plasmid DNA (Weigand et al., 2015). Conversely, C. sporogenes strain CDC24533 belonging to lineage I is a $C$. botulinum Group I strain that probably lost its neurotoxigenic plasmid (Weigand et al., 2015). C. botulinum Group II strains were separated into two distinct lineages (Figure 1B; Supplementary Table S4). Lineage I comprises BoNT/E producing strains only, and while lineage II is dominated by BoNT/B producing strains some BoNT/E and /F producing strains are also present, confirming a previous microarray study (Stringer et al., 2013). Members of C. botulinum Group III also split into two distinct lineages (Figure 1C; Supplementary Table S4). Finally, a single strain of C. botulinum Group IV was examined. In summary, our phylogenetic analysis agrees with previous work that the lack of phylogenetic relationship between the Groups is sufficient to consider each Group as a separate species.

\section{Germinant Receptor Subunits May Have Co-evolved and Could Allow Adaptation to New Environmental Niches}

Under suitable conditions, the dormancy of bacterial spores is broken, and germination occurs. This is often initiated by a GR located in the spore inner membrane responding to nutrient germinants, followed by the release of DPA and partial core hydration. The C. botulinum and C. sporogenes GR is generally composed of three proteins (GerA, GerB, and GerC) that are encoded by their respective ger genes in a multi gene locus (Brunt et al., 2014). The designation, gerX implies that the cognate germinant molecule for the receptor encoded by this gene cluster is unknown. All 156 C. botulinum and C. sporogenes genome sequences were interrogated for ger $X$ clusters and their flanking genes to assess conservation of the ger $X$ cluster genomic organization. Four different types of $g e r X$ cluster were identified (Figure 1D). These different cluster types were further separated into subtypes based on similarity of DNA and predicted protein sequences of their ger $A$, gerB, and ger $C$ genes, together with their genomic organization (Figure 1D). Analysis showed six subtypes displaying a monocistronic ger $A B C$ gene order (ger $X$ type $1 \mathrm{a}-\mathrm{f})$, three subtypes that possess a ger $A B C B$ core, preceded by ger $A B$, ger $B$ or nothing ( $g e r X$ type $2 \mathrm{a}-\mathrm{c}$ ), two subtypes with a bicistronic divergent gerCA and $\operatorname{ger} B$ gene cluster (gerX type $3 \mathrm{a}-\mathrm{b})$, and one with a ger $A C X B B B$ configuration (ger $X$ type 4 ; Figure 1D). Using BLASTP, the similarity within each GerX1 and GerX3 subtype was more than ca. $90 \%$ (except GerX1c 85\%), while the similarity between each subtype was ca. $20-65 \%$.

Comparison of the amino acid sequences of the respective GerA, GerB, and GerC proteins showed that these form clusters according to the GerX subtype (Figure 1E). For example, the GerA, GerB, and GerC proteins of the X2 type each clustered together, as do the GerA, GerB, and GerC components of the $\mathrm{X} 1 \mathrm{a}, \mathrm{X} 1 \mathrm{~b}$ and, X1f subtypes, and the X1c, X1d, and X1e subtypes. Interestingly, the three GerB proteins of the GerX4 type all clustered closely together, and separately from the other GerB proteins (Figure 1E). The fact that all three GerX subunits group together within these four distinct lineages may imply that individual genes within each cluster could have co-evolved, and that the different cluster subtypes may have not arisen through insertional events (except for type 2).

gerX type 1 is an archetypal tricistronic ABC configuration receptor, with six subtypes (Figure $1 D$ ). Each subtype is unique to a single C. botulinum Group. All C. botulinum Group I/C. sporogenes strains possess gerX1a and gerX1d, while several strains in C. botulinum Group I/C. sporogenes lineage II also 
possess gerX1c (Figure 1A). gerX1b and gerX1e are both present in all C. botulinum Group III strains (Figure 1C), and gerX1f is found in C. botulinum Group IV. gerX1a and gerX1d (but not gerX1c) are present in C. botulinum Group I strain ATCC 3502 and C. sporogenes ATCC 15579, and their functionality has been demonstrated (Brunt et al., 2014). The mutation of putative germination gerXA receptor genes revealed that both gerX1s were essential for amino acid stimulated germination in C. botulinum Group I strain ATCC 3502, while in C. sporogenes ATCC 15579 only gerX1d was essential for amino acid stimulated germination (Brunt et al., 2014). The fact that no obvious structural evidence could be found to explain the functional differences between this receptor in C. botulinum and C. sporogenes suggests that the answer may lie in subtle differences between their respective primary amino acid sequences. Interestingly, receptor types gerX1a (C. botulinum Group I/C. sporogenes), gerX1b (C. botulinum Group III), and gerXIf (C. botulinum Group IV), are flanked by homologs of a hypothetical protein immediately upstream of gerXA and a stage II sporulation protein immediately downstream of gerXC. This suggests a conserved location in C. botulinum Group I/C. sporogenes, and in C. botulinum Groups III and IV. However, the other slightly more distantly related gerX1 subtypes (gerX1c, gerX1d, and gerX1e; Figure 1E) are not immediately flanked by the same genes.

The GerXA, GerXB, and GerXC proteins present in GerX type 2 each form a distinct clade separate from other GR proteins (and are shaded green in Figure 1E). GerX type 2 is exclusively possessed by strains of $C$. botulinum Group I and C. sporogenes, and all strains carry a single version of this larger GR gene cluster except for strain 20497 (Figure 1A; Supplementary Table S4). Further examination of the genome of strain 20497 reveals a $\sim 77 \mathrm{~kb}$ deletion compared to the closely related strain 20427, and this $\sim 77 \mathrm{~kb}$ region includes this putative GR gene cluster. The genes encoding the GerX type 2 proteins appear to be in a stable genomic environment, as the GR gene clusters always bear on their $5^{\prime}$ flank an alanine racemase CDS and on their $3^{\prime}$ flank a small conserved hypothetical protein CDS. Alanine racemase is able to convert the germinant L-alanine into the germination inhibitor D-alanine in B. cereus (Dodatko et al., 2009). This locus is conceivably a 'transferable plasticity region' as the configuration and number of GerX CDSs appears to be interchangeable, implying that this region may serve as a recombinational hot-spot for the $\operatorname{ger} X$ subunits. In addition, a small fragment of a gerXA gene apparently was often inserted into the 5 ' end of the first 'extra' gerXB gene of C. botulinum Group I; one example of which has been recently described in some detail (Brunt et al., 2014). The functionality of two of these gene clusters (gerX2b and gerX2c configurations) has recently been tested in C. botulinum Group I strain ATCC 3502 and C. sporogenes ATCC 15579 (Brunt et al., 2014). Mutagenesis of these multi gene loci revealed that neither was able to promote germination alone, although gerX2c formed part of a complex involved in controlling the germination rate in C. sporogenes (Brunt et al., 2014). Moreover, it is conceivable that they could individually respond to some other as yet unknown germinant or environmental niche. It is perhaps pertinent to consider why these putative GR gene clusters vary in their configuration and in particular have additional gerXB genes (except for gerX2a which has an additional $\operatorname{ger} X A$ ). Why does this not appear to be the case with gerXA or gerXC genes? Furthermore, the genomes of all C. botulinum Group I strains also contain a gene encoding an orphan gerB subunit. Although a monocistronic gerA gene subunit has been shown to be functional in C. perfringens, albeit only having a minor role (Paredes-Sabja et al., 2008b; Banawas et al., 2013), there is no current evidence of a functioning monocistronic gerB gene in the genus Clostridium. From our bioinformatics analysis the GerXB protein subunits are up to 457 residues in length and consist of 7-10 transmembrane helices. The GerXB proteins belong to the superfamily of membraneassociated single-component membrane transporters (Setlow, 2014; Moir and Cooper, 2016). However, this homology is largely based on structure as the sequence homology is low. Current evidence also suggests that the GerB protein is responsible for germinant binding (Christie et al., 2008; Christie et al., 2010) and may stabilize and/or influence the quantity of GerC proteins (Cooper and Moir, 2011). Perhaps one attractive proposal is that if the GerXB protein does indeed contain the germinant binding site, then the ability of strains to swap GerXB units or to possess multiple GerXB units may enable them to adapt to exploit new environmental niches.

GerX type 3 is present in some C. botulinum Group I lineage (I) strains and all lineage (II) strains (gerX3a), and in all C. botulinum Group II strains (gerX3b; Figures 1A,B). It is the only complete GR present in C. botulinum Group II, with the caveat that there are currently fewer sequenced C. botulinum Group II genomes available for analysis than there are C. botulinum Group I genomes. Analysis of this locus revealed an organization that is quite different to the 'classical' receptor organization with a GerXA CDS in the middle of the receptor (CA-B; Figure 1D), and a bicistronic transcriptional organization with gerAC and gerB genes in the opposite orientation. The organization of this receptor gene cluster is similar to the single one also observed in $C$. perfringens where the gerK locus includes a monocistronic gerKB in an orientation opposite to that of a bicistronic gerKA-gerKC (Paredes-Sabja et al., 2008b; Banawas et al., 2013). Furthermore, it has been demonstrated that the GerKC protein is the main GR protein involved in nutrient and non-nutrient germination (Banawas et al., 2013). Although no function has yet been formally assigned to this ger gene cluster, the fact that amino acid induced spore germination of three C. botulinum Group II strains has been previously reported makes it the prime candidate for encoding a functional germination receptor (Plowman and Peck, 2002). The GerXA, GerXB, and GerXC proteins present in GerX type 3 each form a separate clade from other C. botulinum GR proteins (shaded blue in Figure 1E).

There is a single example of GerX type 4, the receptor ACxBBB from some strains of C. botulinum Group III (Figures 1C,D). All three GerXB subunits clustered together [and are shaded yellow (Figure 1E)], and while similar to each other were more distantly related to other GerXB proteins (Figure 1E). GerXA and GerXC from GerX type 4 were also distinct from other related GR proteins (Figure 1E). The GerX(x) putative subunit, located in the middle of $C$. botulinum Group III germination 
cluster is a hypothetical protein of 74 residues and comprises a non-cytoplasmic domain (ca. 22 residues) at the $\mathrm{N}$-terminus and a single transmembrane region (ca. 23 residues) in the centre. The protein is also predicted to have its own ribosome binding site and a predicted signal peptide; evidence that it is probably expressed. It also contains the ribosome binding site for the next gene $(\operatorname{ger} X B)$ in this locus. The amino acid sequences of GerX(x) revealed no homology to any other proteins outside of C. botulinum Group III. However, unrelated small (ca. 75 residues) proteins in or adjacent to other GR clusters have been described previously (Paredes-Sabja et al., 2011; Ramirez-Peralta et al., 2013). The functionality of $\operatorname{GerX}(\mathrm{x})$ remains to be tested but it is tempting to speculate that as this protein is only present in C. botulinum Group III, a pathogen strongly associated with animal botulism, this putative receptor subunit may be associated with a particular environmental niche.

\section{Spores Respond to a Diverse Range of Germinants}

Germination of Clostridium spores is usually initiated by germinants that include amino acids and sugars (Table 1), and often proceeds more slowly than that observed with Bacillus (Brunt et al., 2014). Spore germination in C. botulinum Group $\mathrm{I}$ and $C$. sporogenes is triggered by a variety of amino acids, often in combination with L-lactate; although previous studies have described a variable effect of L-lactate (Broussolle et al., 2002; Alberto et al., 2003; Peck, 2009). A literature review of germination characteristics of $C$. botulinum Group I reveals that although most strains germinate with the addition of L-alanine, germination responses are strain, $\mathrm{pH}$, temperature, and buffer dependent (Broussolle et al., 2002; Alberto et al., 2003; Peck, 2009; Brunt et al., 2014). Recently, analysis of C. botulinum strain ATCC 3502 revealed that GerX1a and GerX1d responded to a variety of amino acids and that they act in synergy and cannot function individually. C. sporogenes strain ATCC15579 also responded to a variety of amino acids. Although, only GerX1d was essential, GerX3a and GerX2c GRs form part of a complex involved in controlling the rate of amino acid stimulated germination (Brunt et al., 2014).

Spores of C. botulinum Group II also respond to a variety of amino acids (Table 1) (Ando and Iida, 1970; Ando, 1971; Plowman and Peck, 2002). In contrast to C. botulinum Group I, L-lactate is considered essential for amino acid induced germination in C. botulinum Group II (Plowman and Peck, 2002). The germination responses of C. botulinum Group II is dependent on strain, $\mathrm{pH}$, temperature, and buffer (Ando and Iida, 1970; Ando, 1971; Plowman and Peck, 2002; Peck, 2009).

While various aspects of the physiology and genomics of C. botulinum Group III have been studied in some detail (Eklund and Dowell, 1987; Woudstra et al., 2015), relatively little is known about the properties of their spores or their spore germination characteristics. Based on analysis of the encoded GRs, it is anticipated that these spores will also respond to amino acid germinants. Current knowledge of spore germination in C. botulinum Group IV is also limited. However, one study has shown that spores optimally germinate with a mixture of
L-cysteine, L-lactate, and bicarbonate and sub-optimally with L-alanine, L-lactate, and bicarbonate (Takeshi et al., 1988).

Observed inconsistencies in the results from different publications, together with our own experience, indicate that strain differences and the method used to produce spores, how they are maintained, and which buffer is used to evaluate germination, invariably has a direct effect on germination rates and extents.

\section{SpoVA Is Implicated in Sporulation and DPA Release}

Clostridium and Bacillus spores contain a large store of a 1:1 chelate of $\mathrm{Ca}^{2+}$ and pyridine-2, 6-dicarboxylic acid (DPA) within its core which contributes to spore dormancy and heat resistance (Paidhungat et al., 2000). It has been proposed that the SpoVA proteins are associated with the inner membrane and may form a mechanosensitive channel through which DPA may be transported, and thereby packaged during sporulation (Li et al., 2012; Korza and Setlow, 2013; Velasquez et al., 2014). One line of evidence supporting this hypothesis comes from work showing that SpoVAC can act as a non-selective solute channel when expressed in E. coli (Velasquez et al., 2014). There are three SpoVA proteins, and it is yet to be determined whether all three act together and/or interact with other proteins. For most spore-formers (including C. perfringens), DPA release precedes cortex hydrolysis during germination and is reported to also activate the CwlJ protein (Paidhungat et al., 2001). However, it has recently been found that in Clostridium difficile spore cortex hydrolysis precedes DPA release (Francis et al., 2015). It is presently unknown whether DPA release in C. botulinum and C. sporogenes follows that observed in C. perfringens or C. difficile. A role for SpoVA proteins in clostridial spore germination has been demonstrated in C. perfringens and C. difficile (ParedesSabja et al., 2008a; Donnelly et al., 2016).

In the present study, bioinformatics analysis revealed that strains of C. botulinum Groups I-III and C. sporogenes each contain one gene cluster encoding spoVAC, spoVAD, and spoVAE. In contrast the single strain of C. botulinum Group IV studied to date possesses two gene clusters encoding the SpoVA proteins. C. botulinum SpoVAC, a paralog of SpoVAE, is typically 153 residues long and contains three or four membrane-spanning regions. SpoVAE is approximately 118 residues long and also contains three or four membrane-spanning regions and a predicted signal peptide (C. botulinum Group III). SpoVAD is typically 333 residues long. SpoVAD has been shown to bind specifically to DPA and Ca-DPA (Li et al., 2012). To characterize the functionality of SpoVA proteins in C. sporogenes ATCC 15579, a series of single insertion mutants (spoVAE$1864^{-}$, spoVAC-1862- $2^{-}$spoVAD-1863-) were constructed and subsequently complemented (spoVAE-1864 ${ }^{+}$, spoVAC-1862 ${ }^{+}$, spoVAD-1863 ${ }^{+}$). Phenotypic analysis of the spoVA mutations revealed that the products of all three genes were required for successful sporulation, and complementation restored similar wild type levels of sporulation, except for spoVAE-1864(Figure 2). Furthermore, attempts to complement the spoVAE$1864^{-}$using a plasmid that contained the entire spoVA locus (i.e., 
TABLE 1 | Germinants of Clostridium botulinum Groups I-IV and C. sporogenes spores.

\begin{tabular}{|c|c|c|}
\hline & Germinant & Reference \\
\hline Group I & $\begin{array}{l}\text { L-alanine, L-cysteine, L-methionine, L-serine, } \\
\text { L-phenylalanine, glycine }\end{array}$ & $\begin{array}{l}\text { Broussolle et al., 2002; Alberto et al., 2003; Brunt et al., } \\
2014\end{array}$ \\
\hline C. sporogenes & $\begin{array}{l}\text { L-alanine, L-cysteine, L-methionine, L-serine, } \\
\text { L-phenylalanine, }\end{array}$ & Broussolle et al., 2002; Brunt et al., 2014 \\
\hline Group ॥ & L-alanine, L-serine, L-cysteine, L-threonine, glycine & $\begin{array}{l}\text { Ando and lida, 1970; Ando, 1971; Plowman and Peck, } \\
2002\end{array}$ \\
\hline Group III & No information & - \\
\hline Group IV & L-cysteine, L-alanine* & Takeshi et al., 1988 \\
\hline
\end{tabular}

L-lactate is often required as a co-germinant with the amino acids listed. *sub-optimal germination observed with L-alanine in C. botulinum Group IV.

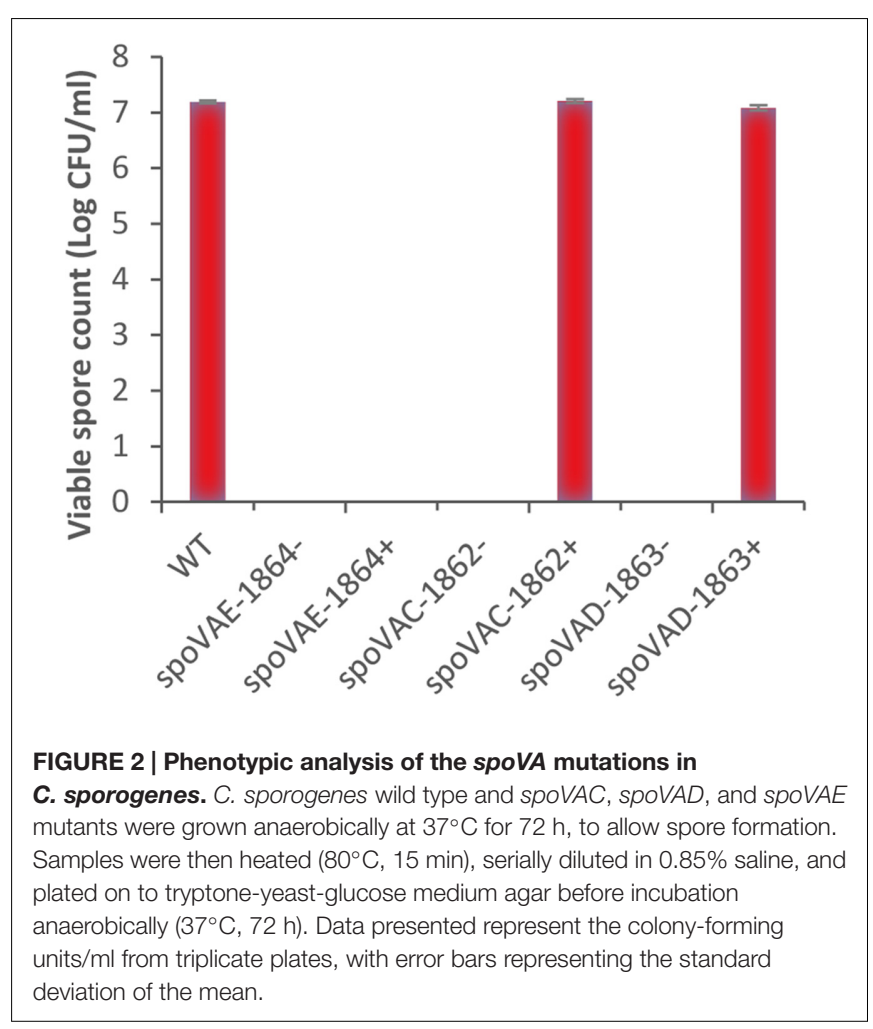

spoVAE, spoVAC, spoVAD) also failed to complement spoVAE$1864^{-}$mutant. The failure of some plasmid complemented mutants to regain wild type sporulation levels in clostridia has been reported previously (Li et al., 2011; Brunt et al., 2014; Meaney et al., 2015). Mutations in the spoVA operon of B. subtilis strains result in the lysis of immature spores during sporulation, most likely due to their lack of DPA (Tovar-Rojo et al., 2002). The cause of this lysis is unknown but it may be due in part to the CLE SleB (see below) which is activated in spores lacking DPA (Tovar-Rojo et al., 2002). Similarly, although we did initially observe occasional endospores produced by SpoVA mutants by phase microscopy, these endospores lysed during sporulation and none were observed at the end of the sporulation experiment. Furthermore, no heat resistant endospores were detected following heating $\left(80^{\circ} \mathrm{C}, 15 \mathrm{~min}\right)$ and subsequent plating on microbiological growth medium. In contrast to our findings for C. sporogenes and those of B. subtilis, mutations of the spoVA operon in C. perfringens and spoVAC in C. difficile did not result in the lysis of immature spores and spores germinated relatively normally, but also had a high water content and decreased heat resistance (Paredes-Sabja et al., 2008a; Donnelly et al., 2016). Taken together, the sequence homology and phenotypic results presented here suggest that the SpoVA proteins may perform a similar role in C. botulinum and C. sporogenes to those reported in Bacillus, specifically the SpoVA proteins may be involved in DPA uptake during sporulation and DPA release during germination. Further studies are required, however, to confirm this assertion.

\section{Spore Cortex Hydrolysis and the Identification of Multiple Enzymes}

In all Bacillus and Clostridium species [except C. difficile (Francis et al., 2015)], the release of DPA and various ions from the germinating spore is followed by the hydrolysis of the peptidoglycan in the spore cortex (Johnstone, 1994). The spore cortex peptidoglycan plays an important role in conserving spore dormancy and heat resistance (Atrih and Foster, 2001; Peck, 2009). Analysis of the spore cortex peptidoglycan reveals that its structure is highly conserved between Bacillus and Clostridium (Atrih and Foster, 2001). Cortex hydrolysis is reliant on activation of preformed CLEs that cleave the spore cortex peptidoglycan. Spores of Bacillus and some Clostridium species contain two redundant CLEs, CwlJ and SleB (Setlow et al., 2009; Paredes-Sabja et al., 2011; Meaney et al., 2015). CwlJ is activated by $\mathrm{Ca}^{2+}$ DPA release from the spore core (Paidhungat et al., 2001). The mechanism of SleB activation remains unknown, although YpeB is required for its localization and may be involved in regulating its activity (Li et al., 2013). C. perfringens and C. difficile have a solitary CLE, SleC, which is essential for peptidoglycan hydrolysis and germination (Miyata et al., 1995; Paredes-Sabja et al., 2009b; Burns et al., 2010). SleC is present as an inactive zymogen which becomes activated by cleavage of Pro-SleC by a Csp protease (Paredes-Sabja et al., 2009a).

The genomes of 156 strains of C. botulinum Groups I-IV and C. sporogenes all contained CLE homologs, with the level of conservation in the predicted protein sequences within each Group $>90 \%$, with the exception of SleB3 and YpeB in Group III (89 and 88\%, respectively), similar to the variation in GerX subunit sequences (Figure 1E). All C. botulinum Groups I and III strains carry at least one copy of sleB, with a single exception 


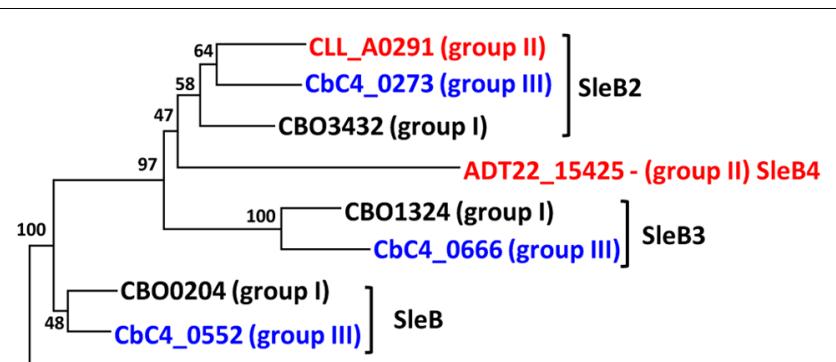

CBCST_23020 - (group III) SleB5

FIGURE 3 | Identification and naming of multiple SleB-like proteins. SleB-like proteins were identified by homology searches in C. botulinum Groups I-III. Amino acid sequences were aligned with MEGA v 7.0, followed by creation of a phylogenetic tree using the Neighbor Joining algorithm. A full list of isolates included and their gene identifier is given in Supplementary

Tables S2 and S4. Values shown at branches represent bootstrap values from 100 replicates.

(Supplementary Table S4). C. botulinum Group I strain Af84 appears to lack a SleB homolog, and this is associated with a deletion of a $\sim 159 \mathrm{~kb}$ region in the genome when compared to C. botulinum Group I strain U21076. This $\sim 159 \mathrm{~kb}$ deletion also includes the SpoVA channel forming proteins. However, there is a second copy of the gene cluster encoding the SpoVA proteins at a different locus. Furthermore, at the site of the deletion, small fragments of spoVAD and spoVAC are observed. All C. botulinum Group I and C. botulinum Group III strains also carry a single copy of a $c w l J$ and $y p e B$ gene. Recent studies have shown that, at least for C. botulinum Group I ATCC 3502, SleB and YpeB are required for optimal germination and that while a gene encoding CwlJ is present, a functional enzyme is not formed (Meaney et al., 2015). These findings are in contrast to B. subtilis in which CwlJ plays a prominent role in degrading the spore cortex (Ishikawa et al., 1998; Yi and Setlow, 2010). Furthermore, studies in our lab (unpublished data) revealed that insertional inactivation of $\mathrm{cwlJ}$ in C. sporogenes ATCC15579 resulted in a decrease in germination rate, indicating that $\mathrm{CwlJ}$ is functional in this strain. Our bioinformatic analysis also revealed the presence of genes encoding four additional 'SleB-like' proteins (tentatively named SleB2, SleB3, SleB4, and SleB5), with at least one example present in each strain of C. botulinum Groups I-III (Figures 3 and 4; Supplementary Table S4).

Interestingly, C. botulinum Group II, which possess the SleC cortex hydrolysis system, also contain sleB2, and strains CB11/1-1, 20536 and ATCC17786 contain a second sleB-like

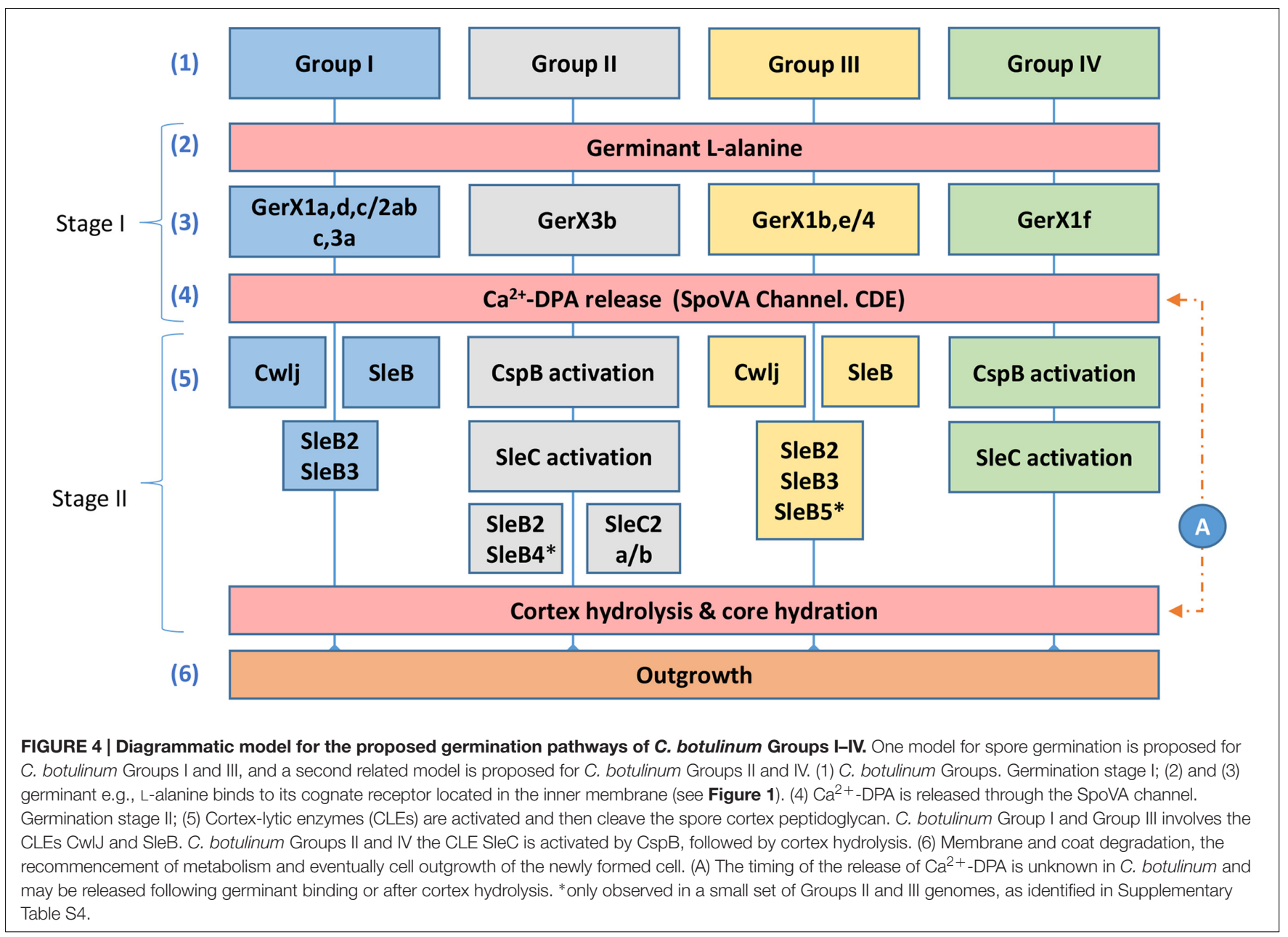


CDS (encoding SleB4). The latter sleB-like gene may, however, be involved in bacterial conjugation as in strains CB11/1-1 and ATCC17786 it is present on a plasmid, situated adjacent to genes predicted to encode the conjugation pilus (Carter et al., 2016). We did not detect genes encoding YpeB or CwlJ homologs in C. botulinum Group II genomes. Similarly, C. botulinum Group IV encodes a SleC cortex hydrolysis system, and does not encode SleB-like homologs. C. botulinum Group II strains also contain a second sleC-like CDS (sleC2a/b; Supplementary Table S4). Alignment and secondary structural analysis revealed that SleC, which is $\sim 443$ residues long, consists of two domains; a SpoIID/LytB domain plus a peptidoglycan-binding domain. SleC2a/b, annotated as a spore CLE, pre-pro-form, is also a multi-domain protein consisting of a SpoIID/LytB domain and 4-5 peptidoglycan-binding domains. SleC2a is $\sim 792$ residues and SleC2b is $\sim 698$ residues. SleC2b, which has one less peptidoglycan-binding domain in comparison to SleC2a, is largely found in C. botulinum Group II type E strains.

SleB2, which is usually annotated in the databases as being 'SleB-like' with a similar C-terminus to $B$. cereus SleB, is $\sim 177$ residues and is defined as a cell wall hydrolase. SleB3 is $\sim 260$ residues, consists of two LysM domains, which are involved in peptidoglycan-binding, and is also associated with the Hydrolase_2 superfamily. Both SleB2 and SleB3 CDSs are immediately preceded by an $y d a O$ element (except in C. botulinum Group II strains). The $y d a O$ element is a riboswitch that is often associated with genes responsible for degradation of polysaccharides in Bacillus (Block et al., 2010). SleB4 is $~ 214$ residues, is only found in three $C$. botulinum Group II strains and belongs to the cell wall hydrolase family. SleB5 is only found in one C. botulinum Group III strain, has two peptidoglycanbinding domains and is annotated as belonging to the spore cortex-lytic family. It is interesting that strains which use the SleC CLE system also contain these SleB-like proteins and it is tempting to speculate that these proteins may be involved in an alternative cortex hydrolysis pathway. Certainly, the functionality of these sleB and sleC-like CDSs merits further investigation, including determination of the ligand for the $y d a O$ motif.

\section{A Diagrammatic Germination Model for Spore Germination in C. botulinum Groups I-IV}

Although the germination mechanisms in Bacillus are better understood, significant progress is now being made in understanding germination processes in Clostridium (ParedesSabja et al., 2011; Kevorkian et al., 2016). Despite this progress, germination mechanisms in C. botulinum Groups I-IV are still relatively poorly understood. Based on our findings and on studies in Bacillus and C. perfringens (Paredes-Sabja et al., 2011) we propose two germination systems for C. botulinum spores (Figure 4). The first system, which applies to strains of C. botulinum Group I (and C. sporogenes) and C. botulinum Group III, involves the recognition of nutrient germinants by their cognate receptor, followed by $\mathrm{Ca}^{2+}$-DPA release through the proposed SpoVA channel (Stage I). In stage II, the CLEs CwlJ and SleB are activated, followed by cortex hydrolysis, membrane and coat degradation, the recommencement of metabolism and eventually cell outgrowth (Figure 4). The second germination system, present in strains of C. botulinum Group II and C. botulinum Group IV, again involves the recognition of nutrient germinants by their cognate receptor, followed by $\mathrm{Ca}^{2+}$-DPA release through the proposed SpoVA channel (Stage I). In stage II, the CLE SleC is activated by CspB (a protein only found in Groups II and IV, see Supplementary Tables S2 and S4), followed by cortex hydrolysis, membrane, and coat degradation, the recommencement of metabolism and eventually cell outgrowth (Figure 4). These are the first models proposed for spore germination in C. botulinum Groups I-IV.

\section{CONCLUSION}

This work describes the first models to be developed of spore germination in C. botulinum Groups I-IV. Of particular interest is the discovery that two different pathways exist which lead to spore germination and subsequently to outgrowth. Spore germination followed the phylogenetic groupings, with germination in C. botulinum Groups I and III similar, and subtly different to that in C. botulinum Groups II and IV. The bioinformatic comparisons and comparative genomics analyses suggest that it is most likely that the individual GerA/B/C components of the GerX clusters have co-evolved, although we cannot exclude a contribution from recombination and horizontal gene transfer. The next few years may be a fascinating period of discovery, in which the different specific role of each class of GR is uncovered.

\section{AUTHOR CONTRIBUTIONS}

JB and MP conceived the study. JB, MP, AvV, AC, and FvdB analysed the data. JB, $\mathrm{AvV}$, and FvdB performed the experiments. JB, MP, AC, and AvV wrote the paper. All authors read and approved the final manuscript.

\section{ACKNOWLEDGMENT}

The authors acknowledge support from the Biotechnology and Biological Sciences Research Council as part of the BBSRC Institute Strategic Programme on Gut Health and Food Safety $\mathrm{BB} / \mathrm{J} 004529 / 1$.

\section{SUPPLEMENTARY MATERIAL}

The Supplementary Material for this article can be found online at: http://journal.frontiersin.org/article/10.3389/fmicb. 2016.01702/full\#supplementary-material 


\section{REFERENCES}

Adam, K. H., Brunt, J., Brightwell, G., Flint, S. H., and Peck, M. W. (2011). Spore germination of the psychrotolerant, red meat spoiler, Clostridium frigidicarnis. Lett. Appl. Microbiol. 53, 92-97. doi: 10.1111/j.1472-765X.2011. 03071.x

Alberto, F., Broussolle, V., Mason, D. R., Carlin, F., and Peck, M. W. (2003). Variability in spore germination response by strains of proteolytic Clostridium botulinum types A, B and F. Lett. Appl. Microbiol. 36, 41-45. doi: 10.1046/j.1472765X.2003.01260.x

Ando, Y. (1971). The germination requirements of spores of Clostridium botulinum type E. Jpn. J. Microbiol. 15, 515-525. doi: 10.1111/j.1348-0421.1971.tb00613.x

Ando, Y., and Iida, H. (1970). Factors affecting the germination of spores of Clostridium botulinum type E. Jpn. J. Microbiol. 14, 361-370. doi: 10.1111/j.1348-0421.1970.tb00536.x

Atrih, A., and Foster, S. J. (2001). Analysis of the role of bacterial endospore cortex structure in resistance properties and demonstration of its conservation amongst species. J. Appl. Microbiol. 91, 364-372. doi: 10.1046/j.13652672.2001.01394.x

Banawas, S., Paredes-Sabja, D., Korza, G., Li, Y., Hao, B., Setlow, P., et al. (2013). The Clostridium perfringens germinant receptor protein GerKC is located in the spore inner membrane and is crucial for spore germination. J. Bacteriol. 195, 5084-5091. doi: 10.1128/JB.00901-13

Barker, G. C., Malakar, P. K., Plowman, J., and Peck, M. W. (2016). Quantification of nonproteolytic Clostridium botulinum spore loads in food materials. Appl. Environ. Microbiol. 82, 1675-1685. doi: 10.1128/AEM.03630-15

Block, K. F., Hammond, M. C., and Breaker, R. R. (2010). Evidence for widespread gene control function by the ydaO riboswitch candidate. J. Bacteriol. 192, 3983-3989. doi: 10.1128/JB.00450-10

Bradbury, M., Greenfield, P., Midgley, D., Li, D., Tran-Dinh, N., Vriesekoop, F., et al. (2012). Draft genome sequence of Clostridium sporogenes PA 3679, the common nontoxigenic surrogate for proteolytic Clostridium botulinum. J. Bacteriol. 194, 1631-1632. doi: 10.1128/JB.06765-11

Broussolle, V., Alberto, F., Shearman, C. A., Mason, D. R., Botella, L., NguyenThe, C., et al. (2002). Molecular and physiological characterisation of spore germination in Clostridium botulinum and Clostridium sporogenes. Anaerobe 8, 89-100. doi: 10.1006/anae.2002.0424

Brown, J. L., Tran-Dinh, N., and Chapman, B. (2012). Clostridium sporogenes PA 3679 and its uses in the derivation of thermal processing schedules for lowacid shelf-stable foods and as a research model for proteolytic Clostridium botulinum. J. Food Prot. 75, 779-792. doi: 10.4315/0362-028X.JFP-11-391

Brunt, J., Cross, K. L., and Peck, M. W. (2015). Apertures in the Clostridium sporogenes spore coat and exosporium align to facilitate emergence of the vegetative cell. Food Microbiol. 51, 45-50. doi: 10.1016/j.fm.2015.04.013

Brunt, J., Plowman, J., Gaskin, D. J., Itchner, M., Carter, A. T., and Peck, M. W. (2014). Functional characterisation of germinant receptors in Clostridium botulinum and Clostridium sporogenes presents novel insights into spore germination systems. PLoS Pathog. 10:e1004382. doi: 10.1371/journal.ppat.1004382

Buchan, D. W., Minneci, F., Nugent, T. C., Bryson, K., and Jones, D. T. (2013). Scalable web services for the PSIPRED protein analysis workbench. Nucleic Acids Res. 41, W349-W357. doi: 10.1093/nar/gkt381

Burns, D. A., Heap, J. T., and Minton, N. P. (2010). SleC is essential for germination of Clostridium difficile spores in nutrient-rich medium supplemented with the bile salt taurocholate. J. Bacteriol. 192, 657-664. doi: 10.1128/JB. 01209-09

Carlin, F., Broussolle, V., Perelle, S., Litman, S., and Fach, P. (2004). Prevalence of Clostridium botulinum in food raw materials used in REPFEDs manufactured in France. Int. J. Food Microbiol. 91, 141-145. doi: 10.1016/S01681605(03)00371-4

Carter, A. T., Austin, J. W., Weedmark, K. A., and Peck, M. W. (2016). Evolution of chromosomal Clostridium botulinum type E neurotoxin gene clusters: evidence provided by their rare plasmid-borne counterparts. Genome Biol. Evol. 8, 540-555. doi: 10.1093/gbe/evw017

Carter, A. T., Paul, C. J., Mason, D. R., Twine, S. M., Alston, M. J., Logan, S. M., et al. (2009). Independent evolution of neurotoxin and flagellar genetic loci in proteolytic Clostridium botulinum. BMC Genomics 10:115. doi: 10.1186/14712164-10-115
Carter, A. T., and Peck, M. W. (2015). Genomes, neurotoxins and biology of Clostridium botulinum Group I and Group II. Res. Microbiol. 166, 303-317. doi: 10.1016/j.resmic.2014.10.010

Christie, G., Gotzke, H., and Lowe, C. R. (2010). Identification of a receptor subunit and putative ligand-binding residues involved in the Bacillus megaterium QM B1551 spore germination response to glucose. J. Bacteriol. 192, 4317-4326. doi: 10.1128/JB.00335-10

Christie, G., Lazarevska, M., and Lowe, C. R. (2008). Functional consequences of amino acid substitutions to GerVB, a component of the Bacillus megaterium spore germinant receptor. J. Bacteriol. 190, 2014-2022. doi: 10.1128/JB. 01687-07

Collins, M. D., Lawson, P. A., Willems, A., Cordoba, J. J., Fernandez-Garayzabal, J., Garcia, P., et al. (1994). The phylogeny of the genus Clostridium: proposal of five new genera and eleven new species combinations. Int. J. Syst. Bacteriol. 44, 812-826. doi: 10.1099/00207713-44-4-812

Cooper, G. R., and Moir, A. (2011). Amino acid residues in the GerAB protein important in the function and assembly of the alanine spore germination receptor of Bacillus subtilis 168. J. Bacteriol. 193, 2261-2267. doi: 10.1128/JB.01397-10

Dodatko, T., Akoachere, M., Muehlbauer, S. M., Helfrich, F., Howerton, A., Ross, C., et al. (2009). Bacillus cereus spores release alanine that synergizes with inosine to promote germination. PLOS ONE 4:e6398. doi: 10.1371/journal.pone.0006398

Dodds, K. (1992). "Clostridium botulinum in the environment," in Clostridium Botulinum: Ecology and Control in Foods, eds A. H. W. Hauschild and K. L. Dodds (New York, NY: Marcel Dekker), 21-52.

Donnelly, M. L., Fimlaid, K. A., and Shen, A. (2016). Characterization of Clostridium difficile spores lacking either SpoVAC or DPA synthetase. J. Bacteriol. 198, 1694-1707. doi: 10.1128/JB.00986-15

Eklund, M. W., and Dowell, V. R. (1987). Avian Botulism. Springfield, IL: Thomas. Francis, M. B., Allen, C. A., and Sorg, J. A. (2015). Spore cortex hydrolysis precedes dipicolinic acid release during Clostridium difficile spore germination. J. Bacteriol. 197, 2276-2283. doi: 10.1128/JB.02575-14

Hatheway, C. L. (1988). “Botulism," in Laboratory Diagnosis of Infectious Diseases: Principles and Practice, eds A. Balows, W. J. Hausler, M. Ohashi, A. Turano, and E. H. Lennete (New York, NY: Springer), 111-133.

Hauschild, A. H. W. (1989). "Clostridium botulinum," in Foodborne Bacterial Pathogens, ed. M. P. Doyle (New York, NY: Marcel Dekker).

Heap, J. T., Kuehne, S. A., Ehsaan, M., Cartman, S. T., Cooksley, C. M., Scott, J. C., et al. (2010). The ClosTron: mutagenesis in Clostridium refined and streamlined. J. Microbiol. Methods 80, 49-55. doi: 10.1016/j.mimet.2009.10.018

Heap, J. T., Pennington, O. J., Cartman, S. T., and Minton, N. P. (2009). A modular system for Clostridium shuttle plasmids. J. Microbiol. Methods 78, 79-85. doi: 10.1016/j.mimet.2009.05.004

Hill, K. K., Xie, G., Foley, B. T., and Smith, T. J. (2015). Genetic diversity within the botulinum neurotoxin-producing bacteria and their neurotoxins. Toxicon 107, 2-8. doi: 10.1016/j.toxicon.2015.09.011

Ishikawa, S., Yamane, K., and Sekiguchi, J. (1998). Regulation and characterization of a newly deduced cell wall hydrolase gene (cwlJ) which affects germination of Bacillus subtilis spores. J. Bacteriol. 180, 1375-1380.

Jacobson, M. J., Lin, G., Whittam, T. S., and Johnson, E. A. (2008). Phylogenetic analysis of Clostridium botulinum type A by multi-locus sequence typing. Microbiology 154, 2408-2415. doi: 10.1099/mic.0.2008/016915-0

Johnson, E. A. (2013). “Clostridium botulinum," in Food Microbiology: Fundamentals and Frontiers, 4th Edn, eds M. P. Doyle and R. L. Buchanan (Washington, DC: ASM Press), 441-463.

Johnstone, K. (1994). The trigger mechanism of spore germination: current concepts. Soc. Appl. Bacteriol. Symp. Ser. 23, 17S-24S. doi: 10.1111/j.13652672.1994.tb04354.x

Kevorkian, Y., Shirley, D. J., and Shen, A. (2016). Regulation of Clostridium difficile spore germination by the CspA pseudoprotease domain. Biochimie 122, 243-254. doi: 10.1016/j.biochi.2015.07.023

Korza, G., and Setlow, P. (2013). Topology and accessibility of germination proteins in the Bacillus subtilis spore inner membrane. J. Bacteriol. 195, 14841491. doi: 10.1128/JB.02262-12

Krogh, A., Larsson, B., von Heijne, G., and Sonnhammer, E. L. (2001). Predicting transmembrane protein topology with a hidden Markov model: application to complete genomes. J. Mol. Biol. 305, 567-580. doi: 10.1006/jmbi.2000.4315 
Kruczkiewicz, P., Mutschalll, S., Barker, D., Thomas, J., Van Domselaar, G., Gannon, V. P. J., et al. (2013). "MIST: a tool for rapid in silico Generation of Molecular Data from Bacterial Genome Sequences," in Proceedings of the International Conference on Bioinformatics Models, Methods and Algorithms: Bioinformatics 2013, Porto, 316-323. doi: 10.5220/000424900 3160323

Li, J., Chen, J., Vidal, J. E., and McClane, B. A. (2011). The Agr-like quorum-sensing system regulates sporulation and production of enterotoxin and beta 2 toxin by Clostridium perfringens type A non-food-borne human gastrointestinal disease strain F5603. Infect. Immun. 79, 2451-2459. doi: 10.1128/IAI.00169-11

Li, Y., Butzin, X. Y., Davis, A., Setlow, B., Korza, G., Ustok, F. I., et al. (2013). Activity and regulation of various forms of CwlJ, SleB, and YpeB proteins in degrading cortex peptidoglycan of spores of Bacillus species in vitro and during spore germination. J. Bacteriol. 195, 2530-2540. doi: 10.1128/JB. 00259-13

Li, Y., Davis, A., Korza, G., Zhang, P., Li, Y. Q., Setlow, B., et al. (2012). Role of a SpoVA protein in dipicolinic acid uptake into developing spores of Bacillus subtilis. J. Bacteriol. 194, 1875-1884. doi: 10.1128/JB.00062-12

Lindström, M., Fredriksson-Ahomaa, M., and Korkeala, H. (2009). "Molecular epidemiology of group I and group II Clostridium botulinum," in Clostridia, Molecular Biology in the Post-Genomic Era, eds H. Brüggemann and G. Gottschalk (Norfolk, UK: Caister Academic Press), 103-130.

Lindstrom, M., Nevas, M., Kurki, J., Sauna-aho, R., Latvala-Kiesila, A., Polonen, I., et al. (2004). Type C botulism due to toxic feed affecting 52,000 farmed foxes and minks in Finland. J. Clin. Microbiol. 42, 4718-4725. doi: 10.1128/JCM.42.10.4718-4725.2004

McClure, P. J. (2006). “Spore-forming bacteria," in Food Spoilage Microorganisms, Vol. 21, ed. C. D. W. Blackburn (Sawston: Woodhead Publishing limited), 579-623.

Meaney, C. A., Cartman, S. T., McClure, P. J., and Minton, N. P. (2015). Optimal spore germination in Clostridium botulinum ATCC 3502 requires the presence of functional copies of SleB and YpeB, but not CwlJ. Anaerobe 34, 86-93. doi: 10.1016/j.anaerobe.2015.04.015

Miyata, S., Moriyama, R., Miyahara, N., and Makino, S. (1995). A gene (sleC) encoding a spore-cortex-lytic enzyme from Clostridium perfringens S40 spores; cloning, sequence analysis and molecular characterization. Microbiology $141(\mathrm{Pt}$, 10), 2643-2650. doi: 10.1099/13500872-141-10-2643

Moir, A., and Cooper, G. (2016). Spore Germination. Microbiol. Spectr. 3, 217-236. doi: 10.1128/microbiolspec.TBS-0014-2012

Page, A. J., Cummins, C. A., Hunt, M., Wong, V. K., Reuter, S., Holden, M. T., et al. (2015). Roary: rapid large-scale prokaryote pan genome analysis. Bioinformatics 31, 3691-3693. doi: 10.1093/bioinformatics/btv421

Paidhungat, M., Ragkousi, K., and Setlow, P. (2001). Genetic requirements for induction of germination of spores of Bacillus subtilis by $\mathrm{Ca}(2+)$-dipicolinate. J. Bacteriol. 183, 4886-4893. doi: 10.1128/JB.183.16.4886-4893.2001

Paidhungat, M., Setlow, B., Driks, A., and Setlow, P. (2000). Characterization of spores of Bacillus subtilis which lack dipicolinic acid. J. Bacteriol. 182, 5505-5512. doi: 10.1128/Jb.182.19.5505-5512.2000

Paredes-Sabja, D., Setlow, B., Setlow, P., and Sarker, M. R. (2008a). Characterization of Clostridium perfringens spores that lack SpoVA proteins and dipicolinic acid. J. Bacteriol. 190, 4648-4659. doi: 10.1128/JB.00325-08

Paredes-Sabja, D., Setlow, P., and Sarker, M. R. (2009a). The protease CspB is essential for initiation of cortex hydrolysis and dipicolinic acid (DPA) release during germination of spores of Clostridium perfringens type A food poisoning isolates. Microbiology 155, 3464-3472. doi: 10.1099/mic.0.030965-0

Paredes-Sabja, D., Setlow, P., and Sarker, M. R. (2009b). SleC is essential for cortex peptidoglycan hydrolysis during germination of spores of the pathogenic bacterium Clostridium perfringens. J. Bacteriol. 191, 2711-2720. doi: 10.1128/JB.01832-08

Paredes-Sabja, D., Setlow, P., and Sarker, M. R. (2011). Germination of spores of Bacillales and Clostridiales species: mechanisms and proteins involved. Trends Microbiol. 19, 85-94. doi: 10.1016/j.tim.2010.10.004

Paredes-Sabja, D., Torres, J. A., Setlow, P., and Sarker, M. R. (2008b). Clostridium perfringens spore germination: characterization of germinants and their receptors. J. Bacteriol. 190, 1190-1201. doi: 10.1128/JB.01748-07

Peck, M. W. (2006). Clostridium botulinum and the safety of minimally heated, chilled foods: an emerging issue? J. Appl. Microbiol. 101, 556-570. doi: 10.1111/j.1365-2672.2006.02987.x
Peck, M. W. (2009). Biology and genomic analysis of Clostridium botulinum. Adv. Microb. Physiol. 55, 320. doi: 10.1016/S0065-2911(09)05503-9

Peck, M. W. (2010). "Clostridium botulinum," in Pathogens and Toxins in Foods: Challenges and Interventions, eds V. K. Juneja and J. N. Sofos (Washington, DC: ASM Press), 31-52.

Peck, M. W., Goodburn, K. E., Betts, R. P., and Stringer, S. C. (2008). Assessment of the potential for growth and neurotoxin formation by non-proteolytic Clostridium botulinum in short shelf-life commercial foods designed to be stored chilled. Trends Food Sci. Technol. 19, 207-216. doi: 10.1016/j.tifs.2007.12.006

Peck, M. W., Plowman, J., Aldus, C. F., Wyatt, G. M., Izurieta, W. P., Stringer, S. C., et al. (2010). Development and application of a new method for specific and sensitive enumeration of spores of nonproteolytic Clostridium botulinum types B, E, and F in foods and food materials. Appl. Environ. Microbiol. 76, 6607-6614. doi: 10.1128/AEM.01007-10

Peck, M. W., and Stringer, S. C. (2005). The safety of pasteurised in-pack chilled meat products with respect to the foodborne botulism hazard. Meat Sci. 70, 461-475. doi: 10.1016/j.meatsci.2004.07.019

Peck, M. W., Stringer, S. C., and Carter, A. T. (2011). Clostridium botulinum in the post-genomic era. Food Microbiol. 28, 183-191. doi: 10.1016/j.fm.2010.03.005

Perutka, J., Wang, W. J., Goerlitz, D., and Lambowitz, A. M. (2004). Use of computer-designed group II introns to disrupt Escherichia coli DExH/Dbox protein and DNA helicase genes. J. Mol. Biol. 336, 421-439. doi: 10.1016/j.jmb.2003.12.009

Plowman, J., and Peck, M. W. (2002). Use of a novel method to characterize the response of spores of non-proteolytic Clostridium botulinum types B, E and F to a wide range of germinants and conditions. J. Appl. Microbiol. 92, 681-694. doi: 10.1046/j.1365-2672.2002.01569.x

Punta, M., Coggill, P. C., Eberhardt, R. Y., Mistry, J., Tate, J., Boursnell, C., et al. (2012). The Pfam protein families database. Nucleic Acids Res. 40, D290-D301. doi: 10.1093/nar/gkr1065

Purdy, D., O'Keeffe, T. A. T., Elmore, M., Herbert, M., McLeod, A., BokoriBrown, M., et al. (2002). Conjugative transfer of clostridial shuttle vectors from Escherichia coli to Clostridium difficile through circumvention of the restriction barrier. Mol. Microbiol. 46, 439-452. doi: 10.1046/j.1365-2958.2002. 03134.x

Quevillon, E., Silventoinen, V., Pillai, S., Harte, N., Mulder, N., Apweiler, R., et al. (2005). InterProScan: protein domains identifier. Nucleic Acids Res. 33, W116-W120. doi: 10.1093/nar/gki442

Ramirez-Peralta, A., Gupta, S., Butzin, X. Y., Setlow, B., Korza, G., LeyvaVazquez, M.-A., et al. (2013). Identification of new proteins that modulate the germination of spores of Bacillus species. J. Bacteriol. 195, 3009-3021. doi: 10.1128/jb.00257-13

Rice, P., Longden, I., and Bleasby, A. (2000). EMBOSS: the European molecular biology open software suite. Trends Genet. 16, 276-277. doi: 10.1016/S01689525(00)02024-2

Sasaki, Y., Takikawa, N., Kojima, A., Norimatsu, M., Suzuki, S., and Tamura, Y. (2001). Phylogenetic positions of Clostridium novyi and Clostridium haemolyticum based on $16 \mathrm{~S}$ rDNA sequences. Int. J. Syst. Evol. Microbiol. 51, 901-904. doi: 10.1099/00207713-51-3-901

Sebaihia, M., Peck, M. W., Minton, N. P., Thomson, N. R., Holden, M. T., Mitchell, W. J., et al. (2007). Genome sequence of a proteolytic (Group I) Clostridium botulinum strain Hall A and comparative analysis of the clostridial genomes. Genome Res. 17, 1082-1092. doi: 10.1101/gr.6282807

Seemann, T. (2014). Prokka: rapid prokaryotic genome annotation. Bioinformatics 30, 2068-2069. doi: 10.1093/bioinformatics/btu153

Setlow, B., Peng, L., Loshon, C. A., Li, Y. Q., Christie, G., and Setlow, P. (2009). Characterization of the germination of Bacillus megaterium spores lacking enzymes that degrade the spore cortex. J. Appl. Microbiol. 107, 318-328. doi: $10.1111 / j .1365-2672.2009 .04210 . x$

Setlow, P. (2014). Germination of spores of Bacillus species: what we know and do not know. J. Bacteriol. 196, 1297-1305. doi: 10.1128/JB.01455-13

Sharpe, A. E., Brady, C. P., Byrne, W., Moriarty, J., O’Neill, P., and McLaughlin, J. G. (2008). Major outbreak of suspected botulism in a dairy herd in the Republic of Ireland. Vet. Rec. 162, 409-412. doi: 10.1136/vr.162.13.409

Sims, G. E., Jun, S. R., Wu, G. A., and Kim, S. H. (2009). Alignment-free genome comparison with feature frequency profiles (FFP) and optimal resolutions. Proc. Natl. Acad. Sci. U.S.A. 106, 2677-2682. doi: 10.1073/pnas.0813249106 
Skarin, H., and Segerman, B. (2014). Plasmidome interchange between Clostridium botulinum, Clostridium novyi and Clostridium haemolyticum converts strains of independent lineages into distinctly different pathogens. PLoS ONE 9:e107777. doi: 10.1371/journal.pone.0107777

Stringer, S. C., Carter, A. T., Webb, M. D., Wachnicka, E., Crossman, L. C., Sebaihia, M., et al. (2013). Genomic and physiological variability within Group II (non-proteolytic) Clostridium botulinum. BMC Genomics 14:333. doi: 10.1186/1471-2164-14-333

Takeshi, K., Ando, Y., and Oguma, K. (1988). Germination of Spores of Clostridium botulinum Type-G. J. Food Prot. 51, 37-38.

Tamura, K., Peterson, D., Peterson, N., Stecher, G., Nei, M., and Kumar, S. (2011). MEGA5: molecular evolutionary genetics analysis using maximum likelihood, evolutionary distance, and maximum parsimony methods. Mol. Biol. Evol. 28, 2731-2739. doi: 10.1093/molbev/msr121

Taylor, R. H., Dunn, M. L., Ogden, L. V., Jefferies, L. K., Eggett, D. L., and Steele, F. M. (2013). Conditions associated with Clostridium sporogenes growth as a surrogate for Clostridium botulinum in nonthermally processed canned butter. J. Dairy Sci. 96, 2754-2764. doi: 10.3168/jds.2012-6209

Tovar-Rojo, F., Chander, M., Setlow, B., and Setlow, P. (2002). The products of the spoVA operon are involved in dipicolinic acid uptake into developing spores of Bacillus subtilis. J. Bacteriol. 184, 584-587. doi: 10.1128/Jb.184.2. 584-587.2002

Treangen, T. J., Ondov, B. D., Koren, S., and Phillippy, A. M. (2014). The Harvest suite for rapid core-genome alignment and visualization of thousands of intraspecific microbial genomes. Genome Biol. 15, 524. doi: 10.1186/PREACCEPT-2573980311437212

van Vliet, A. H., and Kusters, J. G. (2015). Use of alignment-free phylogenetics for rapid genome sequence-based typing of Helicobacter pylori virulence markers and antibiotic susceptibility. J. Clin. Microbiol. 53, 2877-2888. doi: 10.1128/JCM.01357-15
Velasquez, J., Schuurman-Wolters, G., Birkner, J. P., Abee, T., and Poolman, B. (2014). Bacillus subtilis spore protein SpoVAC functions as a mechanosensitive channel. Mol. Microbiol. 92, 813-823. doi: 10.1111/mmi.12591

Weigand, M. R., Pena-Gonzalez, A., Shirey, T. B., Broeker, R. G., Ishaq, M. K., Konstantinidis, K. T., et al. (2015). Implications of genome-based discrimination between Clostridium botulinum Group I and Clostridium sporogenes strains for bacterial taxonomy. Appl. Environ. Microbiol. 81, 54205429. doi: 10.1128/AEM.01159-15

Williamson, C. H., Sahl, J. W., Smith, T. J., Xie, G., Foley, B. T., Smith, L. A., et al. (2016). Comparative genomic analyses reveal broad diversity in botulinumtoxin-producing Clostridia. BMC Genomics 17:180. doi: 10.1186/s12864-0162502-z

Woudstra, C., Le Marechal, C., Souillard, R., Bayon-Auboyer, M. H., Mermoud, I., Desoutter, D., et al. (2015). Draft genome sequences of 17 French Clostridium botulinum Group III strains. Genome Announc. 3:e01105-15. doi: 10.1128/genomeA.01105-15

Yi, X., and Setlow, P. (2010). Studies of the commitment step in the germination of spores of bacillus species. J. Bacteriol. 192, 3424-3433. doi: 10.1128/JB.00326-10

Conflict of Interest Statement: The authors declare that the research was conducted in the absence of any commercial or financial relationships that could be construed as a potential conflict of interest.

Copyright (c) 2016 Brunt, van Vliet, van den Bos, Carter and Peck. This is an openaccess article distributed under the terms of the Creative Commons Attribution License (CC BY). The use, distribution or reproduction in other forums is permitted, provided the original author(s) or licensor are credited and that the original publication in this journal is cited, in accordance with accepted academic practice. No use, distribution or reproduction is permitted which does not comply with these terms. 